\title{
PENDAMPINGAN PENERBITAN JURNAL BIDANG PENDIDIKAN BAGI PENGELOLA JURNAL DI DINAS PENDIDIKAN SEBAGAI MEDIA PUBLIKASI KARYA ILMIAH GURU
}

\author{
Parmin ${ }^{1)}$, Endah Fitriani Rahayu ${ }^{2)}$ \\ 1) Program Studi Pendidikan IPA, Fakultas Matematika dan Ilmu Pengetahuan Alam, Universitas Negeri Semarang, \\ parmin@mail.unnes.ac.id \\ 2) Program Studi Kimia, Fakultas Matematika dan Ilmu Pengetahuan Alam, Universitas Negeri Semarang, \\ endah_danis@mail.unnes.ac.id
}

\begin{abstract}
Abstrak
Kenaikan pangkat dan golongan guru di sekolah dilakukan oleh Dinas Pendidikan setiap tahun. Salah satu komponen yang harus dipenuhi dalam penilaian angka kredit tersebut adalah publikasi ilmiah. Tujuan kegiatan standarisasi penerbitan jurnal ilmiah yang dikelola dinas pendidikan dan kementerian agama di Propinsi Jawa Tengah. Pengelolaan jurnal distandarisasi dengan tata kelola jurnal elektronik yang terakreditasi nasional. Sasaran kegiatan pengelola jurnal di kedua instansi. Metode kegiatan dengan melakukan pendampingan dan simulasi. Kondisi jurnal-jurnal yang menerbitkan artikel guru masih sangat memprihatinkan karena belum sesuai dengan perkembangan penerbitan jurnal elektronik saat ini. Hasil simulasi persyaratan minimal jurnal belum terpenuhi untuk e-ISSN, DOI, etika publikasi, dan belum terbit secara elektronik. Para pengelola jurnal sasaran pengabdian memiliki pengetahuan awal yang sangat minim tentang tata kelola jurnal. Nilai pre tes peserta yang dinilai sebelum kegiatan pendampingan rata-rata 40 sedangkan nilai post test rata-rata 75. Setelah dilakukan pendampingan dapat diambil simpulan pendampingan tata kelola jurnal bagi para pengelola jurnal di Dinas Pendidikan dan Kementerian Agama berdampak pada pengetahuan pengelola jurnal dan tersimulasikan tata kelola jurnal sesuai dengan panduan akreditasi jurnal nasional.
\end{abstract}

Kata Kunci: pendampingan, pengelola jurnal, publikasi.

\begin{abstract}
Promotion and ranks of teachers in schools are carried out by the Department of Education every year. One component that must be fulfilled in the credit rating assessment is scientific publication. Journals publishing teachers' scientific reports have an alarming management system as it is not in line with the current development of electronic journals. This study intends to standardize scientific journal issuance managed by the department of education and the department of religious affairs, central java province, which were the research target. Journal management is standardized by referring to the national accredited electronic journal management. Assistance and simulation were performed in achieving standardization. The simulation revealed that the studied journals have not owned the e-ISSN, DOI, publication ethics, and have not been published electronically. Moreover, the managers of the target journal have limited knowledge about journal management. The pre test scores of the participants before the mentoring were on average 40 , while the post test scores on the average 75 . The mentoring done for the journal managers in both agencies showed a remarkable impact on their knowledge about journal manager as the simulation, which is according to the set national journal accreditation guidelines, was successfully performed.
\end{abstract}

Keywords: assistance, journal manager, publication. 


\section{PENDAHULUAN}

Kenaikan pangkat dan golongan guru di sekolah dilakukan oleh Dinas Pendidikan setiap tahun. Hal ini dalam rangka meningkatkan kesejahteraan guru dan memotivasi guru untuk meningkatkan prestasi pribadi masing-masing. Guru, berdasarkan Undang-Undang Nomor 14 Tahun 2005 tentang Guru dan Dosen, merupakan pendidik professional dengan tugas utama mendidik, mengajar, membimbing, mengarahkan, melatih, menilai, dan mengevaluasi peserta didik. Imbas dari UndangUndang tersebut adalah sebagai tenaga professional, guru mengemban tugas dan wewenang sesuai profesionalisme yang diembannya (Noorjannah, 2014).

Pembinaan karir dan kenaikan pangkat bagi guru professional yang didasarkan pada prestasi kerja dan angka kredit mulai diberlakukan sejak terbitnya Keputusan Menteri Pendidikan dan Kebudayaan Republik Indonesia Nomor 025/O/1995 tentang Petunjuk Teknis Ketentuan Pelaksanaan Jabatan Fugsional Guru. Dalam peraturan tersebut disebutkan bahwa salah satu persyaratan untuk tenaga fungsional Guru Pembina untuk naik ke pangkat yang lebih tinggi diharuskan mengumpulkan angka kredit dari pengembangan profesinya (Iskandar, 2018; Sugiyarti, et al., 2019). Hal ini sejalan dengan ketentuan dalam Undang-Undang Nomor 20 tahun 2003 tentang Sistem Pendidikan Nasional yang mana disebutkan bahwa tenaga professional guru meruoakan tenaga professional yang bertugas merencanakan dan melaksanakan proses pembelajaran, melakukan pembimbingan dan pelatihan, serta melakukan penelitian dan pengabdian kepada masyarakat.

Lahirnya Permenpan Nomor 16 Tahun 2009 tentang jabatan fungsional guru dan angka kreditnya membutuhkan banyak pikiran dan pertimbangan tentang kegiatan guru dan angka kreditnya. Kenaikan golongan guru dari IVa ke IVb, sesuai Pedoman Kegiatan Pengembangan Keprofesian Berkelanjutan (PKB) dan Angka Kreditnya terdapat persyaratan publikasi karya ilmiah (Putra, 2017; Fajriah, et al., 2019). Publikasi ilmiah adalah karya tulis ilmiah yang telah dipublikasikan kepada masyarakat (Noorjannah, 2014). Kebutuhan angka kredit dari unsur karya ilmiah sebanyak 12 untuk kenaikan ke IVb. Jenis publikasi artikel ilmiah yang dimuat di jurnal ilmiah tingkat nasional, propinsi, dan kabupaten/kota dapat digunakan, perbedaan terletak pada angka kredit maksimal yang diperoleh. Artikel ilmiah yang dimuat di jurnal ilmiah tingkat nasional yang terakreditasi angka kreditnya 3 sedangkan jurnal tingkat propinsi angka kredit 2 dan tingkat kabupaten/kota maksimal angka kredit 1.

Publikasi karya ilmiah menjadi sesuatu yang dibutuhkan setiap guru yang akan mengusulkan kenaikan golongan IVb sedangkan media publikasi dalam bentuk jurnal yang sesuai bidang studi yang dikelola dinas pendidikan kabupaten/kota maupun propinsi sangat sedikit jumlahnya. Sejak terbit Permenristekdikti Nomor 9 Tahun 2018 tentang Akreditasi Jurnal Ilmiah maka hanya ada satu sistem akreditasi jurnal di Indonesia yaitu SINTA. Konsekuensi dari sistem SINTA, sampai awal tahun 2019 jurnal bidang pendidikan yang dikelola dinas pendidikan di Jawa Tengah tidak ada satupun yang terakreditasi.

Temuan di lapangan, sebagian guru telah melakukan penelitian, utamanya penelitian tindakan kelas. Penelitian tindakan kelas merupakan metode bagi praktisi pendidikan untuk terlibat dalam penilaian dan peningkatan praktik mereka sendiri. Metode ini dapat menjadi alat untuk membantu guru dalam menganalisis metode pengajaran di kelas dan beradaptasi untuk memecahkan masalah (Gorski, 2015; Arfi \& Ade, 2018). Penelitian yang baik telah dilakukan, akan tetapi produk hasil penelitian yang dilakukan guru terbatas pada laporan penelitian, sangat jarang yang dilanjutkan sampai pada publikasi di jurnal ilmiah. Temuan ini yang menjadikan karya ilmiah guru, jumlahnya sangat terbatas yang diketahui orang lain atau pembaca karena tidak dipublikasikan melalui jurnal yang telah menjadi media online atau elektronik. Pengetahuan guru tentang jurnal terakreditasi sejak sistem menyatu di Sinta juga sangat lemah, bahkan guru tidak tahu tentang perkembangan jurnal ilmiah yang ada. Sementara itu, artikel untuk jurnal bidang pendidikan menjadi sasaran publikasi bagi para dosen, peneliti, dan mahasiswa sehingga menjadi sangat kecil peluang guru bisa publish di jurnal-jurnal yang sebagian besar di kelola oleh perguruan tinggi.

Analisis kebutuhan tentang media publikasi bagi karya ilmiah guru dengan besarnya jumlah guru di Jawa Tengah maka sudah sangat mendesak 
dibutuhkan jurnal ilmiah untuk memfasilitasi karya ilmiah yang dihasilkan oleh guru. Pengelola jurnal bidang pendidikan di Universitas Negeri Semarang, telah memiliki pengalaman mengelola jurnal dari level belum terakreditasi sampai telah terakreditasi menjadi modal penting untuk membantu lembaga pendidikan mitra. Penerbitan jurnal dilakukan oleh lembaga atau organisasi profesi sesuai panduan tata kelola jurnal yang diterbitkan Kemristekdikti pada tahun 2018. Dinas Pendidikan Propinsi Jawa Tengah merupakan mitra paling strategis untuk membantu guru dalam mempublikasikan karya tulis ilmiah. Guru SMA saat ini kewenangan ada di tingkat propinsi. Namun demikian, sesuai hasil diskusi dengan pihak dinas, keterbatasan jumlah pengawai dan minimnya sumber daya pegawai yang mampu mengelola jurnal menjadi kendala utama sehingga merekomendasikan penerbitan jurnal oleh dinas pendidikan, namun pengelola dari forum MGMP tingkat propinsi sesuai bidang studi.

Telah dilakukan kesepakatan dengan pengelola bidang ketenagaan Dinas Propinsi Jawa Tengah bahwa persoalan utama yang menjadi prioritas adalah menyiapkan pengelola jurnal bidang pendidikan. Pengelola jurnal disiapkan dari unsur perwakilan Musyawarah Guru Mata Pelajaran SMA di Jawa Tengah. Dinas Pendidikan pada tahap awal akan mengidentifikasi jurnal-jurnal yang sudah diterbitkan di daerah oleh kelompok guru atau organisasi guru SMA sedangkan kebutuhan jurnal baru akan disiapkan regulasi dan proses perizinan jurnal yang akan diterbitkan. Tim pengabdian dan mitra lembaga dalam hal ini Dinas Pendidikan Provinsi Jawa Tengah dalam menentukan solusi prioritas untuk secara bertahap menyelesaikan permasalahan publikasi karya ilmiah guru. Tim pengelola jurnal dari UNNES yang telah memiliki pengalaman mengelola jurnal terakreditasi nasional akan melakukan pendampingan pada perwakilan forum MGMP SMA di Jawa Tengah. Pihak dinas akan memfasilitasi pelaksanaan pendampingan dengan menghadirkan perwakilan MGMP sesuai sasaran kegiatan pengabdian masyarakat ini.

\section{METODOLOGI PENGABDIAN}

Dinas Pendidikan membutuhkan pengetahuan tentang penerbitan jurnal yang sesuai dengan panduan tata kelola jurnal terakreditasi jurnal nasional sehingga akan dilakukan pendampingan bagi pengelola bidang ketenagaan dinas pendidikan untuk penerbitan jurnal. Pengajuan penerbitan jurnal dilakukan oleh dinas pendidikan dengan pertimbangan agar tata kelola mudah dikontrol. Jurnal yang diterbitkan untuk mempublis artikel guru sehingga dibutuhkan pengelola jurnal dan editor dari guru yang tergabung dalam pengelola jurnal. Penerbitan jurnal di dinas tetapi yang mengelola jurnal karena memiliki sumber daya yang banyak dan sesuai bidang studi untuk menjamin keberlangsungan pengelolaan dan menjaga waktu penerbitan.

Sasaran kegiatan pengabdian kepada masyarakat adalah guru yang tergabung dalam pengelola jurnal yang memiliki ketertarikan dalam penebitan jurnal. Jumlah sasaran pengabdian ditargetkan 20 orang pengelola jurnal di Jawa Tengah yang mewakili setiap bidang studi. Tim pengabdian adalah pengelola jurnal terakreditasi nasional di FMIPA UNNES. Kegiatan akan melibatkan berbagai institusi yaitu; UNNES mengirimkan dosen sebagai tim pengabdian untuk melatih, membimbing dan mendampingi perwakilan pengurus MGMP tentang strategi mempublikasikan jurnal ilmiah sedangkan Dinas Pendidikan Propinsi Jawa Tengah memfasilitasi dengan memberikan rekomendasi kehadiran perwakilan pengelola jurnal.

Kegiatan pendampingan tata kelola jurnal meliputi tahap; persiapan, pelaksanaan dan evaluasi. Kegiatan dilaksanakan melalui tahapan sebagai berikut: Koordinasi tim dosen pengabdian masyarakat dengan Dinas Pendidikan Propinsi Jawa Tengah; penyusunan jadwal pelaksanaan pembimbingan dan pendampingan tata kelola jurnal ilmiah. Kegiatan dilakukan di Kampus FMIPA UNNES; dan tahap evaluasi dibicarakan permasalahan yang muncul baik masalah yang bersifat prinsip, maupun teknis, dan solusi perbaikan untuk keberlanjutan pelaksanaan pembimbingan dan pendampingan.

Evaluasi pelaksanaan kegiatan pengabdian masyarakat, secara rinci mekanisme evaluasi sebagai berikut; ketika sosialisasi tentang pedoman penerbitan jurnal standar terakreditasi nasional di Sinta dilakukan dengan cara pre test dan post test untuk mengukur perubahan pengetahuan peserta, kelengkapan rancangan penerbitan jurnal yang disusun oleh peserta, dan simulasi penilaian akreditasi 
terhadap jurnal baru yang berhasil terbit menggunakan panduan akreditasi jurnal dari Kemenristekdikti (2018).

\section{HASIL DAN PEMBAHASAN}

Kegiatan pendampingan penerbitan jurnal telah diikuti dari perwakilan pengelola Jurnal dari dinas pendidikan dan kementerian agama yang terdiri dari: Dinas Pendidikan Propinsi Jawa Tengah, dan Kementerian Agama Propinsi Jawa Tengah. Perwakilan dinas pendidikan dari kabupaten/kota yang hadir dari: Surakarta, Rembang, Demak, Blora, Cilacap, Brebes, Kebumen, Kota Magelang, Kota Semarang, dan Kabupaten Semarang. Tim pengabdian telah mengundang perwakilan 35 kabupaten/kota di Jawa Tengah, namun setelah dikonfirmasi ada beberapa faktor yang menyebabkan ketidakhadiran pengelola jurnal, terutama karena jurnal di daerah-daerah yang tidak ada perwakilan yang hadir telah lama tidak lagi publish.

Pengetahuan peserta tentang tata Kelola jurnal yang standar nasional diperoleh dengan memberikan soal tes. Perbandingan hasil penilaian pre test dan post test peserta terdapat pada gambar 1 .

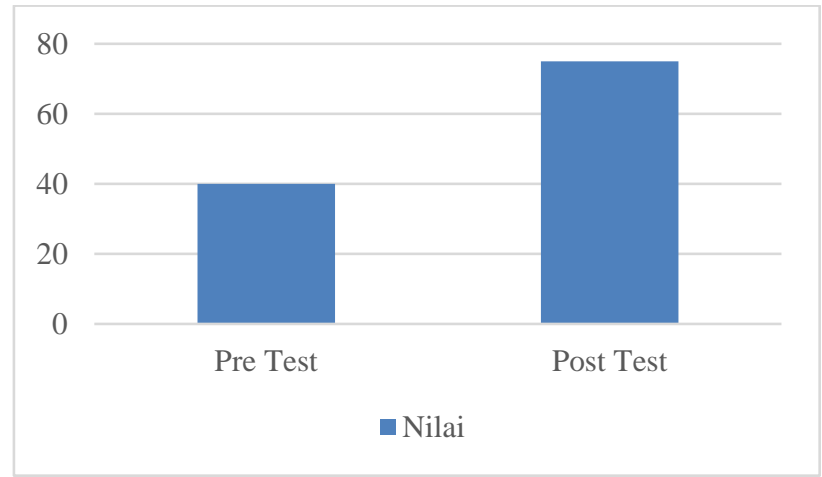

Gambar 1. Pebandingan Hasil Pre Test dan Post Test Peserta Pendampingan

Hasil pendampingan yang telah dilakukan, ditemukan keadaan jurnal-jurnal yang dikelola dinas pendidikan maupun kementerian agama sesuai Tabel 1.

Tahap penyiapan pengusulan akreditasi dilakukan simulasi pengisian evaluasi diri. Jurnal yang dikelola dinas pendidikan tidak dapat diakses melalui website masing-masing sehingga dalam pengabdian masyarakat ini, sebatas melakukan simulasi pada satu jurnal yang digunakan untuk pembelajaran bagi pengelola jurnal lain.
Tabel 1. Kondisi Jurnal di Dinas Pendidikan dan Kementerian Agama

\begin{tabular}{|c|c|}
\hline Kon & Кекол \\
\hline $\begin{array}{l}\text { Tidak memiliki E- } \\
\text { ISSN }\end{array}$ & $\begin{array}{lrr}\text { Melengkapi } & \text { website } & \text { jurnal } \\
\text { dengan konten } & \text { yang } \\
\text { dipersyaratkan } & \text { untuk } \\
\text { pengusulan E-ISSN. } & \end{array}$ \\
\hline Terb & $\begin{array}{l}\text { Menyiapkan kombinasi } \\
\text { perangkat surat elektronik dan } \\
\text { OJS untuk mengelola penerbitan } \\
\text { artikel. }\end{array}$ \\
\hline a & $\begin{array}{l}\text { Penataan kembali personalia } \\
\text { pengelola jurnal elektronik yang } \\
\text { terdiri dari chief editor, editor, } \\
\text { mitra bebestari, dan } \\
\text { administrator. }\end{array}$ \\
\hline $\begin{array}{l}\text { Periode } \\
\text { penerbitan tidak } \\
\text { teratur }\end{array}$ & $\begin{array}{l}\text { Periodesasi penerbitan dibuat } \\
\text { setahun minimal } 2 \text { kali terbit, } \\
\text { setiap terbit minimal } 5 \text { artikel. }\end{array}$ \\
\hline $\begin{array}{l}\text { Kualitas artikel } \\
\text { kurang baik }\end{array}$ & $\begin{array}{l}\text { Secara bertahap mulai } \\
\text { meningkatkan kualitas artikel } \\
\text { terutama pada bagian novelti. }\end{array}$ \\
\hline
\end{tabular}

Pengetahuan 22 orang pengelola jurnal tentang Arjuna (Akreditasi Jurnal Nasional) dan Sinta (Science and Technology Index) terdapat pada Tabel 2.

Tabel 2. Pengetahuan Pengelola tentang Arjuna dan Sinta

\begin{tabular}{|c|c|}
\hline Pertanyaan & Jawaban Peserta \\
\hline $\begin{array}{l}\text { Apakah anda pernah } \\
\text { mendegar Arjuna } \\
\text { (Akreditasi Jurnal } \\
\text { Nasional)? }\end{array}$ & $\begin{array}{l}2 \text { orang pernah mendengar } \\
\text { dan } 20 \text { orang belum pernah } \\
\text { mendengar }\end{array}$ \\
\hline $\begin{array}{l}\text { Apakah anda pernah } \\
\text { mendegar Sinta } \\
\text { (Science and } \\
\text { Technology Index)? }\end{array}$ & $\begin{array}{l}5 \text { orang pernah mendengar } \\
\text { dan } 17 \text { orang belum pernah } \\
\text { mendengar }\end{array}$ \\
\hline $\begin{array}{l}\text { Apakah anda pernah } \\
\text { membuka website } \\
\text { Arjuna (Akreditasi } \\
\text { Jurnal Nasional)? }\end{array}$ & $\begin{array}{l}\text { Semua peserta belum pernah } \\
\text { membuka website Arjuna }\end{array}$ \\
\hline $\begin{array}{l}\text { Apakah anda pernah } \\
\text { membuka website } \\
\text { Sinta (Science and } \\
\text { Technology Index)? }\end{array}$ & $\begin{array}{l}\text { Semua peserta belum pernah } \\
\text { membuka website Sinta }\end{array}$ \\
\hline
\end{tabular}

Hasil simulasi evaluasi diri yang dilakukan terhadap jurnal ORTODIDAKTIKA: Jurnal Kependidikan dan Kebudayaan yang dikelola Dinas Pendidikan Propinsi Jawa Tengah terdapat pada Tabel 3. 
Tabel 3. Kondisi Jurnal di Dinas Pendidikan dan Kementerian Agama

\begin{tabular}{ll}
\hline Komponen Evaluasi Diri & \multicolumn{1}{c}{ Hasil Simulasi } \\
\hline e-ISSN & Tidak ada \\
DOI & Tidak ada \\
Etika Publikasi & Ada, tidak lengkap \\
2 tahun terbit secara & Belum online \\
elektronik & \\
Minimal 5 artikel setiap & Terpenuhi \\
terbit, 2 kali dalam satu & \\
tahun & \\
Terindeks di Google & Proses indeksasi \\
Scholar & \\
Kualitas artikel & Rata-rata artikel kurang \\
& baik \\
Sitasi artikel & Sangat rendah \\
Manajemen tata kelola & Belum menerapkan OJS \\
jurnal & \\
\hline
\end{tabular}

Kegiatan telah dipublikasikan di berbagai media cetak dan elektronik, diantaranya terlihat pada Gambar 1.

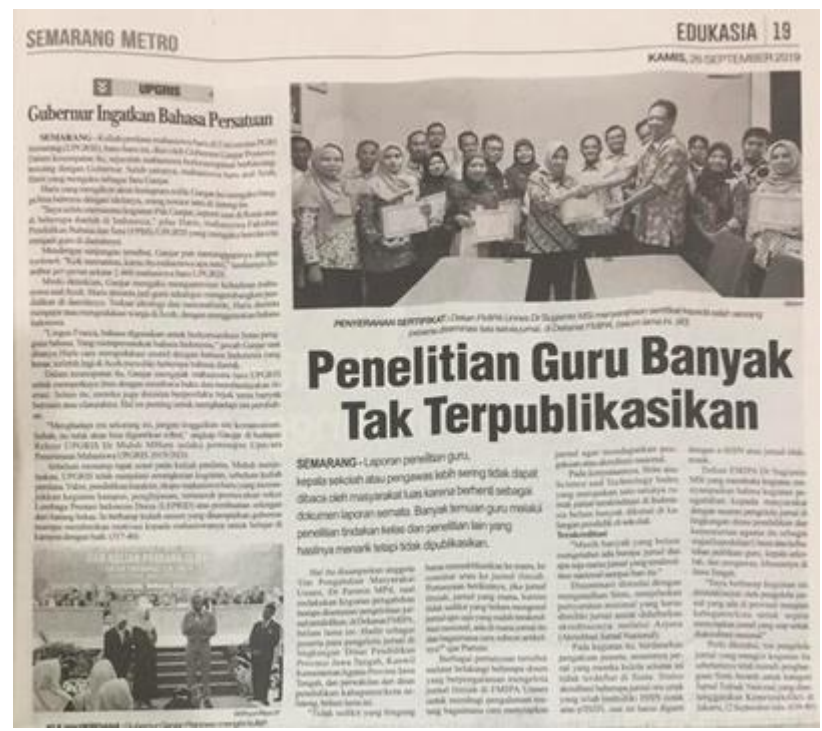

Gambar 1. Publikasi Kegiatan di Suara Merdeka (Halaman: 19, 26 September 2019)

Sinta atau Science and Technology Index yang merupakan satu-satunya rumah jurnal terakreditasi di Indonesia ternyata belum banyak dikenal di kalangan pendidik di sekolah. Masih banyak yang belum mengetahui ada berapa jurnal dan apa saja nama jurnal yang terakreditasi nasional sampai hari ini. Kegiatan dimulai mengenalkan Sinta, menjelaskan persyaratan minimal yang harus dimiliki jurnal untuk didaftarkan akreditasi melalui Arjuna (Akreditasi
Jurnal Nasional) menjadi bagian awal yang disampaikan dalam kegiatan pengabdian masyarakat tim dosen. Peserta yang hadir dari perwakilan Dinas Pendidikan Propinsi Jawa Tengah, Kanwil Kementerian Agama Propinsi Jawa Tengah, dan perwakilan dari Dinas Pendidikan kabupaten/Kota yang juga melakukan kroscek terhadap jurnal-jurnal yang sudah dikelola selama ini dan ternyata tidak terdaftar di Sinta. Status akreditasi beberapa jurnal era cetak, pada saat itu memiliki ISSN cetak atau p-ISSN, saat ini tergantikan dengan dengan e-ISSN atau jurnal elektronik.

Kondisi jurnal-jurnal yang menerbitkan artikel guru masih sangat memprihatinkan karena belum sesuai dengan perkembangan penerbitan jurnal ilmiah saat ini. Di negara - negara maju, keberadaan jurnal ilmiah terbukti memberikan pengaruh yang cukup signifikan terhadap kualitas masyarakat akademisnya (Almah, 2015). Sedangkan jurnal elektronik memiliki standar penerbitan yang harus dipenuhi pada sebuah jurnal (Arianto, 2010; Pardjono, et al., 2017; RistekBrin, 2019). Sebagian besar jurnal bahkan mengalami berhenti mempublis artikel karena berbagai faktor, terutama komitmen pengambil kebijakan dan minimnya informasi yang dimiliki para pengelola tentang tata kelola jurnal elektronik. Lima kondisi umum keadaan jurnal yang ada menunjukkan potensi, artikel yang dipublish tidak mendapatkan pengakuan untuk kenaikan angka kredit guru karena masih versi cetak dan tidak memenuhi persyaratan minimal jurnal elektronik. Pendampingan dimulai dari mengidentifikasi keadaan jurnal-jurnal yang ada pada sasaran kegiatan dan tim pengabdian telah memberikan solusi atas persoalan yang ditemukan.

Peserta yang hadir sebagai sasaran kegiatan, setelah dikonfirmasi pengetahuan tentang tata kelola jurnal elektronik ditemukan tingkat pemahaman yang masih sangat minim tentang tata kelola jurnal elektronik. Ketika ditanya cara mengetahui suatu jurnal terakreditasi atau tidak terakreditasi nasional, sebagian besar peserta menjawab dari membaca di halaman sampul jurnal. Apabila pada halaman sampul jurnal tertulis terakreditasi maka jurnal tersebut berarti terakreditasi sehingga mudah ditemu kenali. Tampilan menu jurnal di era elektronik lebih memudahkan pembaca dan penulis untuk menelusuri (Isa, et al., 2016). 
Pengetahuan ini yang membuktikan bahwa pengetahuan pengelola ada kecenderungan tertinggal dari perkembangan sistem jurnal nasional. Sebagian kecil dari pengelola yang pernah mendegar istilah SINTA sebagai rumah jurnal terakreditasi nasional. Informasi tentang Sinta diperoleh dari mengikuti pelatihan-pelatihan yang narasumbernya dosen, artinya tidak diperoleh melalui kegiatan khusus tentang Sinta.

Pendampingan tata kelola jurnal telah dilakukan, hasil analisis kondisi awal jurnal yang dikelola dinas pendidikan masih jauh dari standar jurnal nasional. Namun setidaknya para pengelola jurnal yang hadir dalam kegiatan pendampingan, terbuka pengetahuan dan wawasan tentang standar tata kelola jurnal yang berlaku saat ini. Sistem tata kelola jurnal yang moderen menggunakan perangkat OJS (Erwin, 2017). Pengetahuan tentang Sinta dan Arjuna menjadi bekal penting dalam melakukan tata kelola jurnal yang membutuhkan waktu panjang. Berbagai persyaratan minimal yang harus dipenuhi sebuah jurnal telah disampaikan karena faktanya dari evaluasi diri yang dilakukan prasyarat minimal belum terpenuhi.

Rekomendasi dari kegiatan pendampingan yang paling penting pada hasil simulasi evaluasi diri jurnal. Setelah dilakukan pengecekan semua jurnal yang pengelolanya hadir belum memiliki e-ISSN atau ISSN elektronik. Semua jurnal telah memiliki p-ISSN atau ISSN cetak sedangkan untuk persyaratan pengajuan akreditasi e-ISSN maka semua jurnal diminta untuk segera mengajukan ISSN elektronik. Cara mendaftarkan telah dipandu pada saat pendampingan sehingga diharapkan jurnal-jurnal sasaran kegiatan segera memiliki e-ISSN. Persyaratan minimal selanjutnya nomor DOI yang ternyata juga belum satupun jurnal memiliki nomor ini maka disimulasikan cara mengajukannya pada saat pendampingan.

Etika publikasi sebagai bagian yang perlu dilengkapi pada jurnal-jurnal sasaran (Gorksi, 2015). Beberapa jurnal bahkan belum memiliki informasi tentang etika publikasi secara khusus karena bagian ini menjadi prasyarat minimal yang harus dipenuhi dan dapat dipenuhi dalam waktu singkat karena tinggal mencantumkan dalam website jurnal. Jumlah artikel dan jumlah minimal penerbitan rata-rata jurnal sudah memenuhi, namun artikel masih terbit secara cetak belum online sehingga untuk pengajuan akreditasi belum dapat dilakukan. Persoalan yang paling serius pada bagian kualitas artikel yang sebagian besar masih jauh dari standar minimal artikel jurnal.

Proses review artikel oleh reviewer jurnal perlu ditingkatkan kualitasnya karena artikel menjadi bagian terpenting pada jurnal. Website untuk memfasilitasi proses dan penerbitan artikel sehingga kualitas artikel menjadi bagian terpenting yang harus ditingkatkan. Artikel yang terbit dijurnal digunakan untuk pengajuan kenaikan pangkat guru, kepala sekolah, dan pengawas. Pengelola jurnal yang hadir dalam pendampingan telah diberikan simulasi mereview artikel sampai pada hasil review yang berkualitas. Artikel yang berkualitas memenuhi kualitas konten dan tidak melanggar etika publikasi (Duwi, et al., (2018). Pengetahuan review penting untuk disampaikan pada editor dan reviewer jurnal, terutama untuk menghindari terjadinya artikel yang plagiasi karena potensi terjadinya besar. Komitmen pengelola jurnal dalam proses pendampingan sangat besar karena berangkat dari ketidaktahuan tentang tata kelola jurnal elektronik dengan nilai pre test ratarata 40. Pengetahuan peserta naik setelah pendampingan dilakukan dengan nilai post test ratarata peserta 75 .

Setelah pendampingan dilakukan para pengelola jurnal menyusun program penyiapan akreditasi masing-masing jurnal. Penyiapan jadwal akreditasi jurnal menunjukkan komitmen yang kuat yang dimiliki peserta pendampingan. Peserta pendampingan juga telah melakukan daftar kekurangan dan kebutuhan masing-masing jurnal untuk penyiapan akreditasi. Kegiatan pengabdian melalui pendampingan bagi pengelola jurnal ini telah menghasilkan rencana tindaklanjut masing-masing jurnal sehingga kegiatan berdampak positif bagi peserta.

\section{PENUTUP}

Para pengelola jurnal sasaran pengabdian memiliki pengetahuan awal yang sangat minim tentang tata kelola jurnal. Setelah dilakukan pendampingan dapat diambil simpulan bahwa memberikan pendampingan tata kelola jurnal bagi para pengelola jurnal di Dinas Pendidikan sangat 
bermanfaat karena ketidaktahuan pengelola yang menjadikan publikasi pada guru, kepala sekolah, dan pengawas cenderung mengalami penurunan secara kuantitas dan kualitas. Secara kuantitas bahan untuk membuat artikel banyak karena banyak juga yang telah melakukan penelitian. Jumlah penelitian yang banyak, potensi artikel juga besar tetapi karena tata kelola jurnal yang ada di dinas pendidikan masih cetak maka sangat sulit menampung artikel yang ada.

Saran yang diberikan pada pihak yang terlibat dalam pengelolaan jurnal di dinas pendidikan dan kementerian agama sebagai berikut; 1) Dinas pendidikan dan kementerian agama menyiapkan website untuk rumah jurnal sehingga pengelola jurnal fokus pada proses pengelolaan artikel; 2) Mendaftarkan e-ISSN untuk semua jurnal sehingga memenuhi syarat minimal sebagai jurnal elektronik; dan 3) Mendaftarkan DOI untuk semua jurnal yang dilakukan secara terpusat agar semua artikel yang terbit mudah diakses dan disitasi.

\section{DAFTAR PUSTAKA}

Almah, H. (2015). Eksistensi Jurnal Ilmiah di Universitas Islam Negeri Alauddin Makassar. Jurnal Ilmu Perpustakaan, Informasi, Kearsipan Khizanah Al-Hikmah, 3(2): 172184.

Arfi, M. \& Ade, T. (2018). Pelatihan Publikasi Karya Ilmiah bagi Guru SMK Al-Inabah Kecamatan Babadan Kabupaten Ponorogo. Jurnal Pengabdian Masyarakat Berkelanjutan, 2(1): 18-21.

Arianto, M. (2010). Membangun Database E-Journal (Penguatan Local Content dan Peningkatan Akses Jurnal-Jurnal Kampus). Al-maktabah, 10(1): 63-81.

Duwi, R., Cicillia, T., \& Hendri, Z. (2018). Analisis Kesalahan dalam Penulisan Karya Ilmiah Mahasiswa Jepang dalam Pembelajaran BIPA. Jurnal Pendidikan Bahasa dan Sastra, 18 (2): $193-210$.

Erwin, D. (2017). Penerapan Open Science di Indonesia agar Riset Lebih Terbuka, Mudah Diakses, dan Meningkatkan Dampak Saintifik. Berkala Ilmu Perpustakaan dan Informasi, 13(1): 25-36.
Fajriah, N., Indah, B., \& Riza. (2019). Bimbingan Penulisan Artikel Ilmiah untuk Publikasi Hasil Penelitian Guru Matematika Kabupaten Banjar. Bubungan Tinggi: Jurnal Pengabdian Masyarakat, 1(2): 106-111.

Gorksi, P. (2015). Teacher Action Research. Critical Multicultural Pavilion: Equity Literacy Institute and an Edchange Project.

Iskandar, A. (2018). Implementasi Ketentuan Kenaikan Pangkat Tenaga Fungsional Guru (Studi di Kabupaten Kota Bumi Lampung Utara). Jurnal Pranata Hukum, 13(1): 72-86.

Isa, S., Soewito, B. \& Gunawan, F. (2016). Pengaruh Perangkat Lunak Managemen Referensi Pada Peningkatkan Motivasi Publikasi Para Pendidik. Ethos (Jurnal Penelitian dan Pengabdian Masyarakat), 4(2): 243-248.

Kemenristekdikti. (2018). Pedoman Akreditasi Jurnal Ilmiah 2018. Direktorat Jenderal Penguatan Riset dan Pengembangan Kementerian Riset, Teknologi, dan Pendidikan Tinggi.

Noorjannah, L. (2014). Pengembangan Profesionalisme Guru Melalui Penulisan Karya Tulis Ilmiah bagi Guru Profesional di SMA Negeri 1 Kauman Kabupaten Tulungagung. Jurnal Humanity, 10(1): 94114.

Pardjono, Nuchron, Surono, Ramdani, S.D. 2017. Analisis Faktor- Faktor Penghambat Produktivitas Publikasi Karya Ilmiah Mahasiswa PPs UNY pada Jurnal Internasional Terindeks. Jurnal Dinamika Vokasional Teknik Mesin, 02(02): 139-147.

Putra, R.W. (2017). Sistem Informasi Kenaikan Pangkat Guru pada UPTD Dinas Pendidikan Kecamatan Singosari. Journal of Information and Technology, 05(01): 13-17.

Ristek-Brin. (2019). Panduan Akreditasi Jurnal Nasional (Arjuna). Direktorat Pengelolaan Kekayaan Intelektual. Direktorat Jenderal Penguatan Riset dan Pengembangan Kementerian Riset dan Teknologi / Badan Riset dan Inovasi Nasional. 
Pendampingan Penerbitan Jurnal Bidang Pendidikan Bagi Pengelola Jurnal di Dinas Pendidikan Sebagai Media

Sugiyarti, S., Nurfitriani, dan Rajab, V. (2019).

Penulisan Artikel Ilmiah untuk Guru Sekolah

Dasar se Kabupaten Bangka. Jurnal

Pengabdian untuk Mu NegeRI, 3(1): 1-5. 